\title{
Building communities, bridging divides: Community technology centers and social capital
}

\begin{tabular}{|c|c|}
\hline \multirow{4}{*}{ Jenna Grzeslo } & Assistant Professor of Digital Media and Journalism. \\
\hline & SUNY New Paltz, New Paltz, NY, USA \\
\hline & Corresponding Author. \\
\hline & grzesloj@newpaltz.edu \\
\hline
\end{tabular}

This paper explores the use of community technology centers (CTCs) by U.S. adults. In this context, CTCs are broadly defined as public, not-for-profit facilities where individuals can access the internet and information communication technologies, the most common of which are public libraries. Furthermore, CTCs are a junction where technology usage and community participation can occur concurrently. Two rounds of data collection using Amazon Mechanical Turk $(n=585)$ and a Qualtrics Survey Panel $(n=330)$ were used to develop a unique measure of social capital generated at CTCs. Through multiple regression analyses, this study identifies that the activities completed at CTCs but not the frequency of attendance are associated with higher levels of community technology center social capital (CTCSC), or rather the feelings of trust and reciprocity captured by our measure.

Grzeslo, J. (2019). Building communities, bridging divides: Community technology centers and social capital. The Journal of Community Informatics. 78-97.

Date submitted: 2018-04-10. Date accepted: 2019-05-15.

Copyright (C), 2018 (the author as stated). Licensed under the Creative Commons AttributionNonCommercial-ShareAlike 2.5. Available at: www.ci-journal.net/index.php/ciej/article/view/1438 


\section{Introduction}

The latest statistics indicate that a majority of Americans now have access to information and communication technologies (ICTs) and the internet: 73 percent of Americans have home broadband access and 77 percent own smartphones (Burger, 2017). On the other hand, Napoli and Obar (2014), through a comprehensive review of ICT access, suggest that mobile internet access is actually inferior to PC-internet access, due to lower connectivity speeds as well as the inability to complete certain functions on mobile devices. Therefore, in areas where mobile phone adoption is high but PC adoption is low, public access to ICTs and the internet serves an important function. In these areas, community technology centers (CTCs), usually attached to libraries, schools or other institutions, play an important role in promoting ICT and broadband access. However, as the literature review section will detail, most of the studies on CTCs were published over a decade ago. Since access to ICTs is evolving, updated research is needed to explore the role of CTCs, despite vast internet and ICT diffusion.

Community technology centers (CTCs) seek to bridge the digital divide by providing access to the internet and ICTs. This paper sets up an exploration into CTCs as a critical component of community development. CTCs commonly provide ICT access to forgotten groups in high-need areas, namely rural and urban communities. In addition to providing much needed technology access, CTCs are also a physical space where members of a community can gather, regardless of background or socioeconomic status. At the same time, CTCs provide access to ICTs, which allow individuals to keep in touch with their existing contacts via email and social networking sites. Given these qualities, this analysis suggests that CTCs have the potential to aid in the generation of social capital, namely feelings of trust, reciprocity and social cohesion.

The concept of social capital has been studied by Bourdieu (1986), Coleman (1988), Putnam (2000), Luloff and Bridger (2003), Woolcock and Narayan (2006), and many others. The impact of technology on social capital has also been studied, but here the conclusions are mixed (Malina \& Ball, 2005; Neves, 2013). On the one hand, technologically mediated communication may isolate individuals and discourage faceto-face interaction, but it also connects people to sources of information and extended social networks, potentially promoting engagement and trust. The impact of CTCs on social capital is even more complicated: whereas they provide access to technology and its potentially isolating and distancing effects, they are also physical locations where people can interact face-to-face. However, as the literature review makes clear, research on CTCs and social capital has not kept pace with changes of technology and patterns of use. The objective of this paper, therefore, is to study how CTCs affect social capital in the present environment.

The paper is structured as follows. In the next section, CTCs are defined, and their roles are clarified. The literature on social capital is then reviewed, with a focus on how 
technology, including CTCs, affects social capital. The paper then discusses the methodology and data, followed by the analysis and findings.

\section{Literature Review}

\section{Defining CTCs}

The purpose of community technology centers (CTCs) is to provide access to ICTs and the internet to populations who may not have regular access to these resources. As Robinson et al. (2015) point out, digital inequalities spill over into a multitude of other activities further deepening inequalities. Various definitions for CTCs exist. The U.S. Department of Education (2005) explains that CTCs provide access to computers and services to those who would otherwise lack access to the technology and their affordances. For the purpose of this study, public computing centers (PCCs), telecenters, and libraries that have computer centers will all be considered CTCs. Therefore, any public access facility that provides free and open access to ICTs and the internet to a community will be classified as a CTC.

CTCs exist in almost every country, generally in rural or deprived urban areas (Ariyabandu, 2009). Access to ICTs is becoming increasingly more important to economic activity, especially in information societies such as the United States (Fuchs $\&$ Horak, 2008). By offering courses in technology literacy, individuals might have the opportunity to increase their human capital, suggesting the potential for economic growth. For instance, Jayakar and Grzeslo (2017) found that CTCs have a small impact on median household income. The objective of this paper is, however, to investigate whether CTCs have an impact on social capital.

\section{Social Capital}

Social capital is one of the most studied and debated theoretical constructs, with various scholars emphasizing the aggregate value of networks versus connections between individuals. For Bourdieu (1986), there are various forms of capital, including cultural, economic, and social. Social capital is based on the size of one's network as well as one's ability to utilize those connections. Comparatively, Coleman (1988) suggests that social capital rests on connections between persons and the value those connections create. Most of the work that builds on social capital theory can be traced to either Bourdieu (1986) or Coleman (1988). Gillies and Edwards (2006) argue that while Bourdieu (1986) was first in exploring social capital, his “... work has been largely sidelined for an emphasis on Coleman's rigid but easily operationalized formula" ( $p$. 45). In addition, Ignatow and Robinson (2017) point out that Bourdieu aimed to "move social science away-from variable-centered hypothesis-testing" (p. 951).

While looking at the role of social capital in community development, Woolcock and Narayan (2006) add that social capital increases capacity by stating, "Social capital refers to the norms and networks that enable people to act collectively" (p. 32-33). Social capital is a theoretical construct that contains several core variables, often 
making it difficult to measure using a survey methodology. Luloff and Bridger (2003) explain, "Social capital develops as trust, reciprocity, and engagement reinforce one another" (p. 206). While individuals need to trust one another in order for social capital to exist, reciprocity is also at the core of this construct. Some argue that everything we do, even generous acts, is due to social capital. We inherently expect a reciprocal favor or at the very least acknowledgement for our thoughtful actions. For poor communities, engagement and reciprocity represent neighbors helping neighbors. On the other hand, some scholars believe that social capital is negative, since it increases the divide in opportunity between those who have it and those who don't. Those who have contacts get ahead while those who do not fall behind.

In his seminal work, Putnam (2000), with reference to Gittell and Vidal (1998), differentiates between the structural dimensions of bridging and bonding social capital. Bonding capital generally represents ties that bind individuals in close relationships, while bridging capital loosely connects people in more distant relationships and acquaintances. Putnam (2000), however, states that “...bonding and bridging are not 'either-or' categories into which social networks can be neatly divided, but 'more or less' dimensions along which we can compare different forms of social capital" (p. 23). These two concepts are closely related to strong and weak ties. Granovetter's "Strength of Weak Ties" argument suggests that weak ties can help individuals get ahead, especially those seeking jobs (Granovetter, 1973). Bridging capital is a parallel concept to weak ties, and bonding capital is similar to strong ties. This is significant for community development. While strong ties and bonding capital help us get by (e.g., watch children when we need an emergency babysitter), weak ties and bridging capital help us get ahead (e.g., inform of us job opportunities in a nearby community) (Woolcock \& Narayan, 2006).

There are competing views on the value of these types of social capital. Some suggest that bonding social capital can actually be bad for communities, since people tend to maintain this form of social capital with those who are similar to themselves, thus increasing intolerance for those who are different or outsiders (Durlauf, 1999; Cavaye, 2004; Gaved \& Anderson, 2004; Arneil, 2006; Jennings, 2007). Although many scholars suggest that weak ties help individuals get ahead, Lin (2001) holds that the poor rely on strong ties for survival. Flora and Flora (2003) explain that communities need both bridging and bonding social capital, but bridging social capital is especially necessary for marginalized or "excluded groups" (p. 227).

\section{Social Capital through CTCs}

Purposeful internet use is important for everyday life and CTCs can provide access to this resource to individuals. Not unlike public libraries, CTCs are a physical space where members of the community can gather (Caidi, 2006). Bourke (2005) explains that through partnerships with other community organizations, libraries can build social capital by connecting their most valuable resources and staff to the public. Ferguson (2012), in a review of social capital generation at public libraries, concludes that these institutions can create social capital if they are impartial and trusted public places. 
Gaved and Anderson (2006) state, "Local ICT initiatives are often driven by a belief that they will generate social capital amongst the recipient population, encourage participation and equity, and improve quality of life" (p. 14). These initiatives are successful when they are embedded in communities and exist over a long period of time (Simpson, 2005).

Next, it is important to look at the relationship between social capital and technology. The development of trust and reciprocity lead to the outcomes of social capital for community members (Sander \& Lee, 2014). Loader and Keeble (2004) explain that ICTs can be used for community development as well as democratic communication and for creating social connections (i.e. social capital). This is complicated by the fact that social capital is usually positively correlated with income. Furthermore, Aabø (2005) states, "Social participation and social inclusion in the information society presuppose information literacy and access to information resources" (p. 208). Merely having the opportunity to access broadband without the income to subscribe to the service, or the information literacy to seek out information, is insufficient. Because of this, Johnson and Griffis (2014) found that library use did not lead to greater social capital among individuals in small towns. Therefore, if only middle- and higher- income individuals are using library services, the effects of the services offered may not be enough to increase social capital.

There is a debate as to whether technology strengthens or weakens social capital in communities (Malina \& Ball, 2005). Specifically, skeptics argue that social media isolate individuals and discourage face-to-face interaction, which can promote social capital. Neves (2013) explores whether there is a neutral, negative, or positive relationship between social capital and internet use and suggests that researchers should look at the mobilization of social capital. Neves (2013) asks, "Does the Internet help people to mobilize their social capital? How and for which kind of actions or resources?" (p. 608). Neves (2013) concludes with yes: access to the internet increases social capital through social connections as well as the additional access to information that the internet provides.

Not all communication that takes place at CTCs is face-to-face interaction with community members. Some patrons of CTCs may also be part of online communities. Wellman, Haase, Witte, and Hampton (2011) explain that "greater use of the Internet may lead to larger social networks with more weak ties and distasteful interaction with some of these ties, resulting in lower commitment to the online community" (p. 449). While excessive internet use may create weak ties, this analysis asks whether CTCs allow individuals to maintain close ties (i.e., family) while creating weak ties (i.e., community contacts) through interaction at CTCs?

CTCs have the potential to create both bridging and bonding social capital. By giving individuals access to the internet, these individuals have the ability to connect with friends via email and social networking sites. Social networks are more likely to support bonding over bridging social capital because social networks bring people with similar views and ideas together (Gibson \& McAllister, 2013; Sajuria et al. 2015). In theory, 
CTCs can generate social capital, but what leads to these feelings of trust and reciprocity?

In addition to theoretical concerns, researchers have also explored the means of measuring social capital. Robalino (2000) suggests the most common way to measure social capital is by measuring one's social connections. Williams (2006) uses separate subscales for bonding and bridging capital, which are adapted from Cohen and Hoberman's (1983) ISEL social support measure. Appel, Dadlani, Dwyer, Hampton, Kitzie, Matni, and Teodoro (2014) provide evidence for a lack of construct and discriminant validity in Williams' (2006) bridging and bonding measures. New ways of measuring social capital may be necessary.

Based on the above literature review on social capital and community technology center usage, several research questions may be raised. First of all, it is important to ask factual questions about the demographic and economic characteristics of CTC users, and then identify the characteristics that are associated with CTC usage. Therefore, the first research question is framed as follows:

RQ1: Among U.S. adults, what characteristics are associated with CTC usage?

A second question is aimed at understanding whether specific types of activities and the skills acquired at CTCs are associated with the generation of social capital. Accordingly, the second research question asks about the types of activities at CTCs.

RQ2: Among U.S. adults, what activities are completed and skills obtained at CTCs?

Finally, the third research question addresses the main objective of this paper, namely the investigation of the factors that contribute to social capital. A problem in addressing this objective is that there is no widely agreed means of measuring social capital in the literature, despite many proposals as discussed above (Robalino, 2000; Williams, 2006). But some of these metrics have also been faulted for lack of construct and discriminant validity (Appel et al., 2014). Accordingly, a new instrument to measure social capital generated by CTCs is defined in the methods section. Using the community technology center social capital (CTCSC) metric, the third research question investigates the predictors of CTCSC.

RQ3: Among U.S. adults, what are the significant predictors of community technology center social capital (CTCSC)?

\section{Methodology}

In order to address the research questions posed above, a survey using Qualtrics Survey Software was employed. Participants consist of U.S. adults $(n=330)$ age 18 and older. 
Participants were obtained using a Qualtrics Survey Panel ${ }^{1}$; beyond age and U.S. residence, no inclusive or exclusive criteria were used to create the panel. Although not a random sample of the U.S. population, this sampling method was chosen because it allows for the collection of data on U.S. adults, in general. Over two-thirds of the participants are women $(71.8 \%, n=237)$. Over half of participants live in a suburban community $(51 \%, n=167)$, while $20 \%$ live in a rural community, $15 \%$ live in a small town, and $14 \%$ live in an urban community. Table 1 presents demographic information for those in the sample, including income, education, and race, as well as the number of individuals who have attended a CTC.

Of the individuals sampled, 128 participants indicated that they visited a CTC, as defined above, in order to access a computer and/or the internet at least once in the last three months. The primary purpose of the facility they visited was most commonly a public library (84\%), but $12 \%$ visited a center that is solely dedicated to computer access, and $4 \%$ visited a center that is focused on economic and employment development. Although only $73 \%$ of Americans have broadband access at home (Burger, 2017), a surprising $98.8 \%$ of participants in the sample have broadband access (Horrigan \& Duggan, 2015). Furthermore, 75\% report that they have access to mobile internet.

1 The Qualtrics Panel was purchased using a grant from the PI's university. The cost of which was $\$ 5$ per participant. 
Table 1: Participant Demographics

\begin{tabular}{|c|c|c|c|c|}
\hline Variable & & Count Overall & Percent Overall & Count CTC \\
\hline \multicolumn{5}{|l|}{ Income } \\
\hline & Below $\$ 20,000$ & 48 & 14.55 & 13 \\
\hline & $\$ 20,000$ - $\$ 29,999$ & 49 & 14.85 & 19 \\
\hline & $\$ 30,000-\$ 39,999$ & 41 & 12.42 & 13 \\
\hline & $\$ 40,000-\$ 49,999$ & 34 & 10.30 & 10 \\
\hline & $\$ 50,000$ - $\$ 59,999$ & 34 & 10.30 & 11 \\
\hline & $\$ 60,000-\$ 69,999$ & 29 & 8.79 & 15 \\
\hline & $\$ 70,000$ - $\$ 79,999$ & 14 & 4.24 & 5 \\
\hline & $\$ 80,000-\$ 89,999$ & 53 & 16.06 & 27 \\
\hline & $\$ 90,000$ or more & 28 & 8.48 & 15 \\
\hline \multicolumn{5}{|c|}{ Education } \\
\hline & Less than High School & 8 & 2.42 & 2 \\
\hline & High School / GED & 78 & 23.64 & 21 \\
\hline & Some College & 83 & 25.15 & 34 \\
\hline & 2-year College Degree & 46 & 13.94 & 17 \\
\hline & 4-year College Degree & 78 & 23.64 & 40 \\
\hline & Masters Degree & 24 & 7.27 & 8 \\
\hline & Doctoral Degree & 7 & 2.12 & 3 \\
\hline & Professional Degree (JD, MD) & 6 & 1.82 & 3 \\
\hline \multicolumn{5}{|l|}{ Race } \\
\hline & White/Caucasian & 274 & 83.03 & 99 \\
\hline & African American & 22 & 6.67 & 11 \\
\hline & Hispanic & 16 & 4.85 & 8 \\
\hline & Asian & 10 & 3.03 & 6 \\
\hline & Native American & 4 & 1.21 & 2 \\
\hline & Other & 4 & 1.21 & 2 \\
\hline
\end{tabular}

\section{Measures}

\section{Social capital}

Despite interest in social capital as an outcome, there is no consensus on an appropriate metric to measure social capital as discussed in the literature review (Robalino, 2000; Williams, 2006). Some of these measures have been criticized for lack of construct and discriminant validity (Appel et al., 2014). Therefore, this paper aims to fill this gap by 
the creation of new measures for bridging and bonding social capital, specifically deriving from CTC use.

To establish a new measure of social capital created through CTCs, (CTCSC scale), two rounds of data collection were conducted. The first round of data was used for an exploratory factor analysis (EFA) on the items to identify which items hang together. ${ }^{2}$ Holbert and Grill (2015) specify that the same data should not be used to conduct an EFA and a confirmatory factor analysis (CFA). Therefore, a second round of data, namely the data used in this study, was collected to conduct a CFA, establishing the fit of the data to the theoretically proposed model. The items used to measure the dimensions of bridging and bonding social capital created at CTCs are presented in Table 1. Unfortunately, the items created were not able to capture separate dimensions of bridging and bonding capital, as all items held neatly together in the EFA. Instead, the product of two rounds of data collection is one measure of community technology center social capital, which consists of 8 items on a 7-point Likert-type scale from 1strongly disagree to 7-strongly agree, $(M=5.32, S D=1.24$, Cronbach's $\alpha=.93)$.

Table 2: Items for Measurement of Bridging and Bonding Social Capital

\section{Bridging Social} Capital

My local technology center is a great place to meet new people.

Going to this tech center makes me feel connected to my community.

I feel a strong connection to those who attend my local tech center.

I believe that I can approach this technology center with internet questions

This technology center is a dependable one.

Bonding Social

Capital

I recommend this technology center to my friends.

Going to a technology center allows me to keep in touch with family through social media.

I like going to this tech center because I can connect with friends through social media.

\section{Internet use}

Prior studies (Rains, 2008) used an "experience using the web" measure developed by Flanagin and Metzger (2000) which asks participants how frequently they use the internet for various purposes, using a 7-point Likert type scale from 1-Never to 7Several times per day. Regarding health information seeking, Dutta-Bergman (2005) found that time spent online is positively correlated with autonomy. For that particular study, individuals were asked to self-report how much time they spend online, averaged

2 Prior to conducting this study with a Qualtrics Survey Panel, an initial round of data collection using Amazon Mechanical Turk $(n=585)$ took place. 
per day (Dutta-Bergman, 2005). Adaptations of both measures were used for this study. Participants were asked how frequently they use the internet for various purposes $(M=$ $6.17, S D=1.47)$ as well as how many hours they spend online each day $(M=7.24, S D$ $=4.39$ ), which is a more precise and less skewed measure of internet use.

\section{Satisfaction with Life}

The satisfaction with the life scale (SWLS) consists of five items on a 7-point Likerttype scale from strongly disagree (1) to strongly agree (7) (Diener, Emmons, Larsen \& Griffin, 1985). The items include "In most ways my life is close to my ideal" and "The conditions of my life are excellent." Diener et al. (1985) report that the SWLS has significant reliability, (Cronbach's $\alpha=.87$ ). SWLS, given its parsimonious measures and reliability, is a frequently used metric in the social sciences. It holds consistent stability across genders and age groups (Pavot \& Diener, 1993). In this study, the SWLS is also reliable, $(M=4.79, S D=1.34$, Cronbach's $\alpha=.89)$.

\section{Control Variables}

Since the sample could consist of any U.S. adults, age 18 and older, several demographic measures were collected and utilized to investigate the differences between CTC users and non-users (RQ1), and to control for other effects in the models (RQ3). The demographic characteristics include age, gender, income, race, level of education, state of residence and number of school-age children in the household.

\section{Results}

RQ1

Research question 1 asks, "Among U.S. adults, what characteristics are associated with CTC usage?" Based on the participants in the study, no significant differences in CTC attendance exist on the basis of race or income. Furthermore, the relationship between gender and CTC usage is approaching significance, with more women visiting the centers than men. A Chi-square test revealed that among CTCs attendees, significantly more have children than not, $\chi_{2}=17.12$, df $=1, p<.001$. An independent sample $t-$ test revealed that those who attend CTCs reported higher levels of empowerment $(M=$ 5.44) than their counterparts that do not visit a CTC $(M=4.92),(t=4.18, \mathrm{df}=269.32, p$ $<$.001). A Chi-square test of independence compared CTC attendance by level of education. ${ }^{3}$ Those with less than a college degree $(57.8 \%)$ were more likely than those with more than a 4-year college degree $(42.2 \%)$ to visit a CTC, $\chi_{2}=4.96$, df $=1, p<$. 05 .

\section{RQ2}

3 Level of education was dummy coded, so this analysis could be conducted. Those with less than a 4year college degree were collapsed into one category, while those with a 4-year degree or more were collapsed into a second category. 
Research question 2 inquires, "Among U.S. adults, what activities are completed and skills obtained at CTCs?" Tables 3 and 4 illustrate the activities that individuals report completing at CTCs, with figures representing how many individuals report completing said activities. The most common activities are, not surprisingly, general searches for information, followed by email, and utilizing Microsoft Word.

Table 3: Most common activities at CTCs

\begin{tabular}{llllllll}
\hline SEARCH & $\begin{array}{l}\text { SEND } \\
\text { EMAIL }\end{array}$ & $\begin{array}{l}\text { MICRO. } \\
\text { WORD }\end{array}$ & $\begin{array}{l}\text { S OCIAL } \\
\text { MEDIA }\end{array}$ & SHOPPING & $\begin{array}{l}\text { RECEIVE } \\
\text { HELP }\end{array}$ & JOBS & RESUME \\
\hline 95 & 50 & 39 & 35 & 33 & 32 & 31 & 29 \\
\hline
\end{tabular}

These categories are not mutually exclusive, which highlights the vast array of tasks and experiences that individuals can have at CTCs.

Table 4: Additional activities at CTCs

\begin{tabular}{llllllll}
\hline $\begin{array}{l}\text { VISUAL } \\
\text { MEDIA }\end{array}$ & MUSIC & EXCEL & $\begin{array}{l}\text { D A T A } \\
\text { ENTRY }\end{array}$ & $\begin{array}{l}\text { M E E T } \\
\text { E W } \\
\text { PEOPLE }\end{array}$ & $\begin{array}{l}\text { COMPUTER } \\
\text { CLASES }\end{array}$ & $\begin{array}{l}\text { POWER } \\
\text { POINT }\end{array}$ & $\begin{array}{l}\text { COMPLETE } \\
\text { HOMEWORK }\end{array}$ \\
\hline 27 & 26 & 25 & 21 & 21 & 20 & 19 & 14 \\
\hline
\end{tabular}

Table 5 outlines which skills are obtained at CTCs. This is a critical component of the mission of many CTCs, which seek to provide physical access to technology but also skills training and digital literacy. The top skill people obtain is the ability to search for relevant information. Other skills include sending emails, using social media, using Microsoft Word, creating a resume, and creating an email account. These may all seem like basic skills, but to individuals with limited to no access to ICTs and the internet, acquiring these fundamental skills is the foundation for future internet usage. When asked how these skills were acquired, one participant states, "I helped other people, and in doing so, learned myself." More commonly, participants stated that they obtained these skills from library and/or CTC staff or from taking technology courses.

Table 5: Most common skills obtained at CTCs

\begin{tabular}{llllll}
\hline SEARCH & $\begin{array}{l}\text { SEND } \\
\text { EMAIL }\end{array}$ & $\begin{array}{l}\text { SOCIAL } \\
\text { MEDIA }\end{array}$ & WORD & RESUME & $\begin{array}{l}\text { EMAIL } \\
\text { ACCOUNT }\end{array}$ \\
\hline 49 & 42 & 36 & 34 & 33 & 29 \\
\hline
\end{tabular}


RQ3

Research question 3 addresses the main goal of this study by asking, "among U.S. adults, what are the significant predictors of community technology center social capital (CTCSC)?" Table 6 includes the descriptions of the variables used in the regression analysis.

Table 6: Variable Descriptions

\begin{tabular}{|c|c|}
\hline Variable Name & Definition \\
\hline ATTENDANCE & How frequently individuals visit a CTC \\
\hline METRICSKILLS & Count of number of skills obtained at CTC \\
\hline METRICACTIVITIES & Count of number of activities completed at CTC \\
\hline SWLS & Satisfaction with life scale \\
\hline TIMEONLINE & Amount of time spent online (from $0-24$ hours per day) \\
\hline EDUCATION & $\begin{array}{l}\text { Recoded variable representing less than or greater than a } 4 \text {-year college } \\
\text { degree }\end{array}$ \\
\hline CTCSC & Community technology center social capital \\
\hline
\end{tabular}

Table 7 displays the descriptive statistics for the variables used in the model. Since not all participants visit CTCs or have acquired skills through CTCs, the number of observations for each variable vary accordingly. Among CTC attendees, 74 (57.8\%) have less than a 4-year college degree.

Table 7: Descriptive statistics

\begin{tabular}{llll}
\hline Variables & Obs. & Mean & Std. dev. \\
\hline ATTENDANCE & 128 & 2.48 & 1.36 \\
METRICSKILLS & 100 & 4.22 & 2.87 \\
METRICACTIVITIES & 127 & 4.07 & 3.17 \\
SWLS & 330 & 4.79 & 1.34 \\
TIMEONLINE & 330 & 7.24 & 4.39 \\
CTCSC & 128 & 5.32 & 1.24 \\
\hline
\end{tabular}

Table 8 displays a correlation matrix for the variables in the model. The Pearson's $r$ values for most of the variables are acceptable for the regression model. The measures for METRICSKILLS and METRICACTIVITIES are nearing the .60 threshold, which 
could cause multicollinearity. Therefore, both of those measures will not be used in the same regression model.

Table 8: Correlation matrix

\begin{tabular}{|c|c|c|c|c|c|}
\hline & $\begin{array}{l}\text { ATTENDANC } \\
\text { E }\end{array}$ & $\begin{array}{l}\text { METRICSKIL } \\
\text { LS }\end{array}$ & $\begin{array}{l}\text { METRICACTIVITI } \\
\text { ES }\end{array}$ & $\begin{array}{l}\text { S W L } \\
\text { S }\end{array}$ & $\begin{array}{l}\text { TIMEONLI } \\
\text { NE }\end{array}$ \\
\hline ATTENDANCE & 1 & & & & \\
\hline METRICSKILLS & .10 & 1 & & & \\
\hline $\begin{array}{l}\text { METRICACTIVITI } \\
\text { ES }\end{array}$ & .32 & .57 & 1 & & \\
\hline SWLS & .16 & .23 & .12 & 1 & \\
\hline TIMEONLINE & .28 & .19 & .19 & .06 & 1 \\
\hline
\end{tabular}

Finally, we turn to our main question of interest and the primary analysis of this study. To analyze the effects of the predictors on CTCSC, an OLS regression model was run. The results of the regression analysis are presented in Table 9, which shows that time spent online, satisfaction with life, and the CTC activity metric positively and significantly predict CTCSC. On the other hand, frequency of CTC attendance is not a significant predictor, $p=.61$. This is an interesting finding, as intuitively one would expect that people who attend a center more frequently would feel a greater connection to that center. On the other hand, our findings did not support this basic assumption, suggesting that the relationship between individual characteristics and feelings of trust and social embeddedness are actually more complex than previously expected. Finally, EDUCATION has a negative and significant coefficient in this model.

Table 9: Predictors of CTCSC

\begin{tabular}{lllll}
\hline Predictor Variable & B & SE B & $\boldsymbol{t}$ & $\boldsymbol{p}$ \\
\hline Overall Model & 2.37 & .33 & 7.17 & .000 \\
ATTENDANCE & .04 & .07 & .66 & .51 \\
METRICACTIVITIES & .08 & .03 & 2.68 & .008 \\
SWLS & .49 & .06 & 8.12 & .000 \\
TIMEONLINE & .04 & .02 & 2.22 & .03 \\
EDUCATION & -.50 & .17 & -2.90 & .004 \\
\hline
\end{tabular}

$\left(R^{2}=.46, \mathrm{~F}(5,121)=20.35, p<.001\right)$ 


\section{Discussion}

RQ1 explores the demographic profile of CTC users compared to non-users, as the sample was not restricted to only CTC patrons. In line with past research, parents of school-age children are the foundation of communities, and they are more likely to visit CTCs compared to their childless counterparts. Findings also suggest that those with lower levels of education are also more likely to visit a CTC. Although the findings of this study cannot suggest causation, those who attend CTCs reported higher levels of empowerment than those who do not attend CTCs. This is interesting from two potential angles. First, it could mean that CTCs empower individuals, but it could also mean that individuals who are more empowered are more likely to visit a CTC. This relationship should be explored further in future research.

Regarding CTC attendance, what is perhaps most interesting is that most of the participants have home broadband access, even those living in rural areas. One of the primary purposes of CTCs is to provide internet access to those who lack home access. On the other hand, there were a significant number of people in the study who still visited a CTC to complete activities online, despite having access at home. This suggests that there are benefits beyond access that can be obtained through CTCs. Among the 128 participants who have visited a CTC in the last three months, $78 \%(n=$ 100) indicate that they have acquired a technical or internet related skill from that CTC. This illustrates that not only are CTCs a means to bridge the digital divide for those who need access to the internet and ICTs, but they also go beyond access and provide individuals with skills training as well, suggesting that CTCs are actively working towards bridging the second-level digital divide. ${ }^{4}$

RQ2 asks which activities are completed at CTCs and what skills are obtained through these hubs. Searching for relevant information represents both the most common activity completed at CTCs as well as the most common skill obtained at CTCs. The most common activities and skills also suggest that CTC patrons may require a basic level of ICT training. More advanced skills were included as options on the questionnaire, but most participants cited learning how to complete basic internetrelated tasks such as creating an email account and sending an email. This is not to say that these individuals will not go on to learn more advanced skills later, since individuals base their confidence on their past experiences (Schunk, 1989). For instance, studies suggest that the more time individuals spend online, the more confident they become with ICTs. As self-efficacy increases, skills also improve over time (Eastin \& LaRose, 2000; Tsai \& Tsai, 2003).

Finally, RQ3, the main research question of this study, seeks to identify the predictors of CTCSC. If CTCs are to be used not only as a means of bridging the digital divide but also as a mechanism for encouraging community development, then understanding what builds trust in and through these facilities is crucial. Interestingly, more frequent visits to a CTC does not lead to higher levels of CTCSC. Although the survey asked how

4 The second-level digital divide represents a gap in internet-related skills as well as a gap in how and why individuals use ICTs and the internet. 
frequently individuals visited a CTC, participants were not asked to indicate how much time is spent at the CTC on each visit or even each week. Perhaps, the actual amount of time spent at the CTC is a predictor of CTCSC but not the frequency of visits, especially if individuals attend the CTC frequently but only for short periods of time.

Using ICTs is associated with greater social capital. For instance, Gaved and Anderson (2006) state, "Both bonding and bridging capital can be positively affected by the introduction of ICT within the community, helping strengthen bonds within the locality and also maintain contact with distant friends and relatives, and negotiate with external bodies such as local authorities" (p. 14). Communities and groups with high levels of bonding capital are associated with more frequent use of ICTs (Williams, 2005). Interestingly, the number of activities individuals complete at CTCs is positively and significantly associated with CTCSC. This suggests that the more tasks individuals complete at their local technology center, the closer they feel to that center. On the other hand, it may also indicate that the more tasks an individual completes at a CTC, the closer she feels to her close contacts who are not at a CTC.

One's satisfaction with life is also a significant predictor of CTCSC. SWLS is often used as a control in multiple regression models of this nature. It is expected that individuals who are unhappy, in general, are less likely to feel connected to community members and to community spaces. Therefore, including this variable in the model is a means of controlling for individuals that are dissatisfied in general. Not surprisingly, SWLS accounts for a significant amount of the variance explained by the model. When asked if there was anything else about the CTC that you would like to share, one participant notes, "Mostly it is just a safe, clean, dependable place to hook up to the internet while getting away from the demands of day to day life. A relaxed convenience." This quote may speak to the relationship described above.

Overall time spent online is also a significant predictor of CTCSC. The relationship between these two variables has not been fully unpacked. For instance, had our measure of community technology center social capital truly captured both individual elements of bridging and bonding capital, then we would expect a negative relationship between time spent online and bridging capital and a positive relationship between time spent online and bonding capital. This means there would be a correlation between time spent online at the CTC and maintaining close contacts, and a negative correlation between time spent online and gaining new contacts. Unfortunately, bridging and bonding capital are difficult dimensions to measure with quantitative scales and were not captured by two rounds of data collection. Rather, the CTCSC scale is composed of elements of both bridging and bonding social capital that can occur simultaneously at community technology centers. Perhaps, individuals who spend more time online feel closer to their CTC because technology centers provide them with a physical space to complete online tasks, obtain technical assistance, and gain new skills. On the other hand, this relationship needs to be explored further in future studies, especially qualitative studies that can deeply delve into these complex relationships in a way that quantitative measures cannot. 
Finally, EDUCATION has a negative and significant coefficient in this model. This should be interpreted, based on the analysis, that those with greater education (i.e. a 4year degree or more) are associated with less CTCSC, once other factors are controlled. This is an important finding, as most studies suggest that those with greater income, generally correlated with higher levels of education, are associated with more social capital. This relationship should also be parsed out further in future studies.

\section{Conclusion}

This study, while yielding novel and significant results, has some limitations that can be mitigated through future research. Namely, additional data analysis can better explain CTC attendance, possibly through using logistic regression.

Next, these findings suggest what tasks are completed and what is gained through attendance at CTCs, but this study lacks the rich qualitative data needed to explain the mechanisms by which individuals become motivated to attend CTCs as well as how they go about gaining new skills.

Finally, as discussed in the section on the demographics of the sample, most of the participants have broadband access at home. This does not reflect the figures reported by the FCC or Pew Internet Research. This may suggest that while this study has a reliable sample, it deviates from the U.S. population on this dimension. This is something to consider, moving forward, as future studies explore this area. Namely, past research suggests that not having home broadband access is a predictor of CTC usage, but despite this, over $30 \%$ of the participants still report visiting a CTC.

Funding Statement: This project received support from the Don Davis Program in Ethical Leadership, in the Donald P. Bellisario College of Communications, at Penn State University.

Ethics approval: Penn State University Institutional Review Board. 


\section{References}

Aabø, S. (2005). The role and value of public libraries in the age of digital technologies. Journal of Librarianship and Information Science, 37(4), 205-211. doi: 10.1177/0961000605057855

Appel, L., Dadlani, P., Dwyer, M., Hampton, K., Kitzie, V., Matni, Z., Teodoro, R. (2014). Testing the validity of social capital measures in the study of information and communication technologies. Information Communication \& Society, 17(4), 398-416. doi:10.1080/1369118X.2014.884612

Ariyabandu, R. (2009). Role of Telecenters as knowledge networks: Successes and challenges. ESCAP Technical Paper, IDD/TP-09-06. Bangkok, Thailand: United Nations Economic and Social Commission for Asia and the Pacific. Retrieved from http://telecentres.mfep.gov.dz/fileadmin/user_upload/bibilio_files/ Role of telecentre.pdf

Arneil, B. (2006). Diverse communities: The problem with social capital. Cambridge, UK; New York: Cambridge University Press.

Bourdieu, P. (1986). The forms of capital. In J. Richardson (Ed.), Handbook of theory and research for the sociology of education (pp. 241-258). Westport, CT: Greenwood.

Bourke, C. (2005). Public libraries: Building social capital through networking. Australasian Public Libraries and Information Services, 18(2), 71-75.

Burger, A. (2017). Pew: U.S. smartphone ownership, broadband penetration reached record levels in 2016. Telecompetitor. Retrieved from http:// www.telecompetitor.com/pew-u-s-smartphone-ownership-broadbandpenetration-reached-record-levels-in-2016/

Caidi, N. (2006). Building "civilisation competence": A new role for libraries? Journal of Documentation, 62(2), 194-212. doi:10.1108/00220410610653299

Cavaye, J. (2004). Social capital: A commentary on issues, understanding and measurement. Australia: Observatory PASCAL-Place Management. Social Capital and Learning Regions, 1-27.

Cohen, S., \& Hoberman, H. M. (1983). Positive events and social supports as buffers of life change stress. Journal of Applied Social Psychology, 13(2), 99-125.

Coleman, J. S. (1988). Social capital in the creation of human capital. American Journal of Sociology, 94(1), S95-S120. doi:10.1086/228943

Diener, E., Emmons, R. A., Larsen, R. J., \& Griffin, S. (1985). The satisfaction with life scale. Journal of Personality Assessment, 49(1), 71-75. doi:10.1207/ s15327752jpa4901_13

Durlauf, S. N. (1999). The case "against" social capital. Focus (Madison), 20(3), 1-5. Retrieved from http://www.irp.wisc.edu/publications/focus/pdfs/ foc203.pdf\#page $=1$

Dutta-Bergman, M. J. (2005). Developing a profile of consumer intention to seek out additional information beyond a doctor: The role of communicative and motivation variables. Health Communication, 17(1), 1-16. doi:10.1207/ s15327027hc1701_1

Eastin, M. S. \& LaRose, R. (2000). Internet self-efficacy and the psychology of the digital divide. Journal of Computer-Mediated Communication, 6(1), online. 
doi: 10.1111/j.1083-6101.2000.tb00110.x

Ferguson, S. (2012). Are public libraries developers of social capital? A review of their contribution and attempts to demonstrate it. Australian Library Journal, 61(1), 22-33.

Flanagin, A. J. \& Metzger, M. J. (2000). Perceptions of Internet information credibility. Journalism and Mass Communication Quarterly, 77, 515-540.

Flora, C.B., \& Flora, J.L. (2003). Social capital. In D.L. Brown, \& L.E. Swanson (Eds.), Challenges for Rural America in the Twenty-First Century (pp. 215-227). University Park, PA: The Pennsylvania State University Press.

Fuchs, C., \& Horak, E. (2008). Africa and the digital divide. Telematics and Informatics, 25(2), 99-116. doi:10.1016/j.tele.2006.06.004

Gaved, M., \& Anderson, B. (2006). The impact of local ICT initiatives on social capital and quality of life. University of Essex, Ipswich. Retrieved from http:// oro.open.ac.uk/31143/

Gibson, R. K., \& McAllister, I. (2013). Online social ties and political engagement. Journal of Information Technology \& Politics, 10(1), 21-34. doi: $10.1080 / 19331681.2012 .712461$

Gillies, V., \& Edwards, R. (2006). A qualitative analysis of parenting and social capital: Comparing the work of Coleman and Bourdieu. Qualitative Sociology Review, 2(2), 42-60.

Gittell, R. J., \& Vidal, A. (1998). Community organizing: Building social capital as a development strategy. Thousand Oaks, CA: Sage Publications.

Granovetter, M. S. (1973). The strength of weak ties. American Journal of Sociology, 78(1), 1360-1380.

Holbert, R., \& Grill, C. (2015). Clarifying and expanding the use of confirmatory factor analysis in journalism and mass communication research. Journalism \& Mass Communication Quarterly, 92(2), 292-319. doi:10.1177/1077699015583718

Horrigan, J. \& Duggan, M. (2015). Home broadband 2015. Pew Internet Research. Retrieved from http://www.pewinternet.org/2015/12/21/home-broadband-2015/

Ignatow, G. \& Robinson, L. (2017). Pierre Bourdieu: Theorizing the digital. Information, Communication, \& Society, 20(7), 950-966.

Jayakar, K., \& Grzeslo, J. (2017). Local economic impacts of investments in community technology centers: An empirical investigation. The Journal of Community Informatics, 13(1), 137-151. Retrieved from http://ci-journal.net/index.php/ciej/ article/view/1304

Jennings, J. (2007). Race, neighborhoods, and the misuse of social capital (1st ed.). New York: Palgrave Macmillan.

Johnson, C. A., \& Griffis, M. R. (2014). The effect of public library use on the social capital of rural communities. Journal of Librarianship and Information Science, 46(3), 179-190. doi:10.1177/0961000612470278

Lin, N. (2001). Social capital: A theory of social structure and action. Cambridge, UK; New York: Cambridge University Press.

Loader, B., \& Keeble, L. (2004). Challenging the digital divide? A literature review of community informatics initiatives. York, UK: Joseph Rowntree Foundation.

Luloff, A.E., \& Bridger, J.C. (2003). Community agency and local development. In D.L. Brown, \& L.E. Swanson (Eds.), Challenges for Rural America in the Twenty- 
First Century (pp. 203-213). University Park, PA: The Pennsylvania State University Press.

Malina, A., \& Ball, I. (2005). ICTs and community and suggestions for further research in Scotland. Journal of Community Informatics, 1(3). Retrieved from http:// www.ci-journal.net/index.php/ciej/article/view/214/171

Napoli, P. M., \& Obar, J. A. (2014). The emerging mobile internet underclass: A critique of mobile internet access. The Information Society, 30(5), 323-334. doi: 10.1080/01972243.2014.944726

Neves, B. B. (2013). Social capital and internet use: The irrelevant, the bad, and the good. Sociology Compass, 7(8), 599-611. doi:10.1111/soc4.12059

Pavot, W., \& Diener, E. (1993). The affective and cognitive context of self-reported measures of subjective well-being. Social Indicators Research, 28(1), 1-20. doi: 10.1007/BF01086714

Putnam, R. D. (2000). Bowling alone: The collapse and revival of American community. New York: Simon \& Schuster.

Rains, S. A. (2008). Seeking health information in the information age: The role of Internet self-efficacy. Western Journal of Communication, 72(1), 1-18. doi: 10.1080/10570310701827612

Robalino, D. (2000). Social capital, technology diffusion and sustainable growth in the developing world. Santa Monica, CA: RAND Corporation.

Robinson, L., Cotten, S. R., Ono, H., Quan-Haase, A., Mesch, G., Chen, W., Schulz, J., Hale, T., \& Stern, M. J. (2015). Digital inequalities and why they matter. Information, communication \& society, 18(5), 569-582. https://doi.org/ 10.1080/1369118X.2015.1012532

Sajuria, J., vanHeerde-Hudson, J., Hudson, D., Dasandi, N., \& Theocharis, Y. (2015). Tweeting alone? An analysis of bridging and bonding social capital in online networks. American Politics Research, 43(4), 708-738. doi.org/ $10.1177 / 1532673 X 14557942$

Sander, T., \& Lee, T. P. (2014). A concept to measure social capital in social network sites. International Journal of Future Computer and Communication, 3(2), 105-107. doi:10.7763/IJFCC.2014.V3.278

Schunk, D. H. (1989). Self-efficacy and achievement behaviors. Educational Psychology Review, 1(3), 173-208. doi:10.1007/BF01320134

Simpson, L. E. (2005). Community informatics and sustainability: Why social capital matters. The Journal of Community Informatics, 1(2), 102-119. Retrieved from http://www.ci-journal.net/index.php/ciej/article/view/210

Tsai, M. J., \& Tsai, C. C. (2003). Information searching strategies in web-based science learning: The role of Internet self-efficacy. Innovations in Education and Teaching International, 40(1), 43-50.doi:10.1080/1355800032000038822

U.S. Dept. of Education. (2005). Frequently asked questions. Retrieved from https:// www2.ed.gov/programs/comtechcenters/faq.html

Wellman, B., Haase, A. Q., Witte, J., \& Hampton, K. (2001). Does the internet increase, decrease, or supplement social capital?: Social networks, participation, and community commitment. American Behavioral Scientist, 45(3), 436-455. doi: $10.1177 / 00027640121957286$ 
Williams, K. H. (2005). Social networks, social capital, and the use of information and communications technology in socially excluded communities: A study of community groups in Manchester, England, University of Michigan. Retrieved from http://hdl.handle.net/2027.42/39370

Williams, D. (2006). On and off the 'Net: Scales for social capital in an online era. Journal of Computer-Mediated Communication, 11(2), 593-628. doi:10.1111/j. 1083-6101.2006.00029.x

Woolcock, M. \& Narayan, D. (2006). Social capital: Implications for development theory, research, and policy revisited. In A. Bebbington (Ed.) The search for empowerment: Social capital as idea and practice at the World Bank (pp. 31-62) Bloomfield, CT: Kumarian Press. 